\title{
Descriptive Investigation of Government Events and Public Interest Analysis Using Google Trends between Pictorial Health Warnings Policy Implementation and Electronic Nicotine Delivery Systems Ban in India
}

\author{
Ashima Sarin ${ }^{1}$, Hitesh Singhavi ${ }^{2}$, Akshay Patil ${ }^{3}$, Ravi Mehrotra ${ }^{4}$, Sanjay Seth ${ }^{5}$, Rajiv Janardhanan ${ }^{6}$ \\ ${ }^{1}$ Research Scholar and Director, Amity Institute of Public Health, Amity University, Noida, Uttar Pradesh, India \\ and Sambandh Health Foundation, Gurugram, Haryana, India, ${ }^{2}$ Consultant Head \& Neck Surgeon, Fortis \\ Hospital, Mulund, Mumbai, Maharashtra, ${ }^{3}$ Statistician, Clinical Research Secretariat, Tata Memorial Hospital, \\ Parel, Mumbai, Maharashtra, ${ }^{4}$ Chief Executive Officer, India Cancer Research Consortium (ICMR-DHR), IRCS \\ Building, New Delhi, India, ${ }^{5}$ Director, Sambandh Health Foundation, Gurugram, Haryana, India, ${ }^{6}$ Research \\ Scholar, Amity Institute of Public Health, Amity University, Noida, Uttar Pradesh, India
}

\begin{abstract}
Background: A sequential descriptive analysis of the government events related to $85 \% \mathrm{PW}$ implementation and ENDS ban is lacking. There is also a dearth of public interest analysis in such policy making.

Objectives: To descriptively analyse the sequence of government events in both the policies and evaluate the public interest analysing trends from the respective events.

Method: Government events in India on $85 \%$ PWs were collected from media articles ranging from October 2014 to April 2016 while on ENDS ban, the information was obtained from Ministry of Health \& Family Welfare, Government of India from August 2018 to December 2019. We compared Google Trends relative search volume data for 'smoking causes cancer', 'smoking danger', 'pictorial', 'ITC limited' as keywords for Pictorial Health Warnings from April 2014 to April 2016 (Policy A) while keywords such as 'electronic cigarettes, 'Vape', 'Juul' were used as surrogate for ENDS ban from October 2017 to October 2019 (Policy B).

Results: According to the Google trends analysis, 'pictorial' was searched significantly more in Policy A time period (4298 vs 2599) while 'Vape' had distinctly more searches in Policy B time period (6136 vs 1042). However, the volume of difference between the two policies time period was significantly higher for Vape (5094 vs 1699).

Conclusion: Strategy and experiences from delayed implementation of pictorial health warnings has laid down the path for faster enactment of future anti-tobacco policies.
\end{abstract}

Keywords: Pictorial Warnings, Electronic Nicotine Delivery Systems (ENDS), Government Actions, Tobacco products.

\section{Corresponding Author:}

Ashima Sarin

Research Scholar and Director, Amity Institute of Public Health, Amity University, Noida, Uttar Pradesh and Sambandh Health Foundation, Gurugram, Haryana, India

E-mail: ashima.sarin@sambandhhealth.org

\section{Introduction}

Approximately 1 billion people living on this planet consume tobacco in some form (smoking/smokeless). It is estimated that half a billion human beings would prematurely die due its usage unless they quit ${ }^{1,2}$. There are various ways in which anti-tobacco health workers have been working hard against mighty tobacco industry 
to save such lives. One of the ways being the Pictorial Warnings showing ill-effects of tobacco on the packaging itself $^{3}$. However, there has been strong resistance from tobacco industry against such mechanism to reduce the usage of tobacco all over the world. India's long journey of pictorial health warnings (PW) implementation from $40 \%$ to $85 \%$ on tobacco products was no different than in other countries. The Government of India notified the 85\% PWs on October 15, 2014 for the implementation on April 1, 2015 but these were implemented after a delay of over 12 months on April 1, 2016 ${ }^{4}$. There was much learning from the implementation of pictorial health warnings for future policies such as recent ban on Electronic Nicotine Delivery Systems (ENDS) in India on $18^{\text {th }}$ September 2019.

Apart from the Government's will, success of the implementation of any government policy largely depends on the existing public interest. Google is one of the most popular search engines in the world ${ }^{5}$. Google trends give real-time data thus has proven to be a potential tool to gauge public interest ${ }^{6}$. Such data of public interest between the two events can give us potential reason for the difference in the success. This research paper analyses Government actions and public interest on PW and ENDS policies in their respective time periods.

\section{Method and Material}

We examined the government events on $85 \%$ pictorial health warnings and ENDS ban in India, comparing two time periods by means of actions taken by the government in both the policies. Time period for Policy A events was from October 2014 to April 2016 and for Policy B from August 2018 to December 2019. The information on government events on $85 \%$ PWs were collected from the media reports provided by a PR agency 'Comma Communications Management', which tracked news everyday related to tobacco. For ENDS ban Government events were taken from Ministry of Health \& Family Welfare, Government of India. The data was collected for further analysis into an excel sheet. Events were defined as those which were related to policy announced by the Government on (i) Pictorial health warnings, such as notification, delay in implementation of $85 \%$ PWs, contempt by Rajasthan High Court, Committee on Subordinate Legislation formed to assess PWs, etc. (ii) In case of ENDS Ban announcements made by the Government such as Advisory issued by the MoHFW, the White Paper by Indian Council of Media
Research, the Ordinance, etc. The collected Government events were then manually classified as pro and anti, based on the following criteria: (1) Pro actions included statements in favour of both the policies (2) Negative government events included statements against both the policies. The classifications of the government events were cross-checked by a second researcher to remove any bias or error. We collected the events of both the policies i.e., PWs \& ENDS Ban. Events of both policies were then compared in order to observe for government actions. In order to gauge the public interest on both the policies, we compared the Google Trends relative search volume data for terms 'smoking causes cancer', 'smoking danger', 'pictorial', 'ITC limited' as keywords for Pictorial health warnings policy from April 2014 to April 2016 (Policy A) while keywords 'electronic cigarettes, 'Vape', 'Juul', 'ENDS' were used as surrogate for ENDS ban from October 2017 to October 2019 (Policy B). India was selected as the geography for all the searches on Google Trends.

Statistical Analysis: Normal distribution of the scores was tested using the Kolmogorov-Smirov test and homogeneity of variance was tested using Levene's test. Categorical data was represented in Frequency form and continuous data was presented as the Mean \pm SD or median (IQR). The Spearman correlation coefficient was used to measure the associations, descriptive analysis was performed to identify distribution of variables included in the study. Mann Whitney test was used to compute difference between the two groups. All analysis was tested with two-sided hypothesis testing and significance was considered at a p-value less than 0.05. Statistical analyses were performed using SPSS (Statistical Package for Social Sciences) IBM Corp. Released 2017. IBM SPSS Statistics for Windows, Version 25.0. Armonk, NY: IBM Corp.

\section{Results}

A total of 19 Government events occurred on Pictorial health warnings from October 2014 to April 2016. Of these $10(52.63 \%)$ were pro policy events and $9(47.36 \%)$ were anti policy events. On ENDS, a total of 6 Government events took place. Of these $100 \%$ were pro policy events (Table-1).

In the present study, it was observed that, while the media was reporting real time, each and every move of the Government, all stakeholders as media, lawyers, public health activists, tobacco industry, were also 
playing their roles. It is evident from the table above that even though the Government was in favour of the $85 \%$ PWs, there was huge pressure from the tobacco industry, Committee on Subordinate Legislation (CoSL) and public health activists. After many interferences and reports from the CoSL, Public Notice was finally issued. This was taken as affirmation by the public health activists who were monitoring this issue closely. On $16^{\text {th }}$ March 2016, the Ministry issued a statement that there will be no course of change in warnings and it will stick to $85 \%$ implementation from April 1, 2016 (Table-1).

The Government was alert in policy on ENDS ban. The MoHFW took proactive actions right from the beginning immediately after there were studies from western world on the multitude of harms of electronic cigarettes. Table 2 represents how the Indian Government then took faster actions for ban on ENDS. An Advisory issued by the MoHFW to all states of India followed by the White Paper on ENDS in India on the World No Tobacco Day 2019 was evidence that the Government was all set to ban ENDS in India and indeed, within three months of this white paper, ENDS was banned in India through an Ordinance ${ }^{7}$. During this time, various stakeholders including public health activists, media, lawyers got involved quickly. Soon after the Ordinance, the Lok Sabha \& Rajya Sabha supported the Bill on ENDS and without any anti actions, the ENDS ban came into force on December 5, $2019^{8}$. Table 2 shows the intensity of pro actions that took place in the preceding 7-8 months to the Ordinance, despite of attempts by the anti-forces to derail the process (Table-2).
Relative Google search volumes for Policy A, included 'smoking causes cancer', 'smoking danger', 'pictorial', 'ITC limited' representing $85 \%$ PWs policy. Total volume search for keyword search of 'smoking causes cancer' was 873 (0-21 per week), 'smoking danger' was 443 (0-15 per week), 'pictorial' was 6491 (37-100 per week), 'ITC limited' was 3584 (13-58 per week) when searched together (Figure-1). While relative Google search volumes for Policy B, included electronic cigarettes was 1373 (7-100 per week), 'Vape' was 807 (5-12 per week), 'Juul' was 140 (1-4 per week) for the time period from October 2017 to October 2019 when searched together (Figure-2).

Total volume of searches between the two policies could not be compared as they were from different time periods. Thus, from the above results 'Pictorial' and 'Vape' were compared for both the time periods Policy A (2014-2016) and Policy B (2017-2019) as these search words were most comparable (Figure-3 and 4). Total volume search for 'Pictorial' and 'Vape' was 4298 (2567 per week) and 2599 (4-100 per week) respectively for Policy A time period (Figure 3) while total search volume for 'Pictorial' and 'Vape' was 1042 (6-18 per week) and 6136 (6-100) respectively for Policy B time period (Figure-4). Thus, in Policy A time period Pictorial was searched significantly higher than Vape while in Policy B time period Vape was searched more than pictorial.

However, Figure-5 represents that volume of difference between the time periods (5094 vs 1699) for Vape was significantly higher than pictorial $(\mathrm{p}<0.001)$ (Figure -5).

Table 1: Government Events on 85\% Pictorial Health Warnings

\begin{tabular}{|l|l|c|}
\hline Date & Government Events on 85\% Pictorial Health Warnings (PWs) & Pro/Anti event \\
\hline 15-Oct-14 & Government notified 85\% PWs & Pro \\
\hline 25-Feb-15 & $\begin{array}{l}\text { Favourable statement from the Minister of Health \& Family Welfare (MoHFW), Government } \\
\text { of India }\end{array}$ & Pro \\
\hline 18-Mar-15 & $\begin{array}{l}\text { Committee on Subordinate Legislation (CoSL) formed and gave report to the Health Ministry } \\
\text { to hold 85\% GHWs }\end{array}$ & Anti \\
\hline 23-Mar-15 & PWs were put on hold by the MoHFW & Anti \\
\hline 25-Mar-15 & Favourable statement by the Union Health Minister on 85\% PWs & Pro \\
\hline 03-Apr-15 & Favourable statement by the Union Health Minister on 85\% PWs & Pro \\
\hline 05-Apr-15 & Prime Minister of India made a favourable statement on PWs & Pro \\
\hline 01-May-15 & $\begin{array}{l}\text { Finance Minister of India made a favourable statement that Government fully supports the 85\% } \\
\text { pictorial health warnings }\end{array}$ & \\
\hline
\end{tabular}




\begin{tabular}{|l|l|c|}
\hline Date & Government Events on 85\% Pictorial Health Warnings (PWs) & Pro/Anti event \\
\hline 16-Jul-15 & $\begin{array}{l}\text { Civil Societies invited by the Committee on Subordinate Legislation (CoSL) for } \\
\text { implementation of 85\% PWs discussion (this was a delay strategy) }\end{array}$ & Anti \\
\hline 19-Aug-15 & Minister of Health, Government of India maintained status quo on 85\% PWs & Anti \\
\hline 27-Aug-15 & $\begin{array}{l}\text { Affidavit submitted by the MoHFW in Rajasthan High Court seeking for 6-months extension to } \\
\text { implement 85\% PWs }\end{array}$ & Anti \\
\hline 10-Sep-15 & Report by the CoSL to the Ministry to hold these large PWs & Anti \\
\hline 25-Sep-15 & Pictorial Health Warnings be implemented on 1st April 2016 & Anti \\
\hline 18-Dec-15 & Clarification sought by the CoSL on 85\% PWs from the Health Ministry (delay strategy) & Anti \\
\hline 08-Jan-16 & CoSL seeks clarification on 85\% PWs from Health Ministry & Pro \\
\hline 19-Feb-16 & Public notice in newspapers to implement 85\% PWs effective April 1, 2016 & Anti \\
\hline 11-Mar-16 & Members of the CoSL denied 85\% PWs stating it is unfair for tobacco industry & Pro \\
\hline 16-Mar-16 & $\begin{array}{l}\text { MoHFW issued a favourable statement that no change will be made to course of the warnings } \\
\text { and large PWs will be implemented }\end{array}$ & Pro \\
\hline 01-Apr-16 & Implementation of the 85\% PWs from 1st April 2016 & \\
\hline
\end{tabular}

Table 2: Government Events on ENDS Ban

\begin{tabular}{|l|l|c|}
\hline Date & Government Events on ENDS Ban & Pro/Anti event \\
\hline 28- Aug-2018 & Advisory by Union Health Ministry to ban ENDS & Pro \\
\hline 31-May-2019 & White Paper by ICMR on health hazards of E-Cigarettes & Pro \\
\hline $18-$ Sep-19 & The Ordinance on ENDS & Pro \\
\hline 27-Nov-19 & Bill on ban of ENDS passed by Lok Sabha & Pro \\
\hline 2-Dec-19 & Bill on ban of ENDS passed by Rajya Sabha & Pro \\
\hline 5-Dec-19 & Law on ENDS ban passed & Pro \\
\hline
\end{tabular}

\section{Pictorial Warnings Timeline \& Google keyword searches Graph}

120

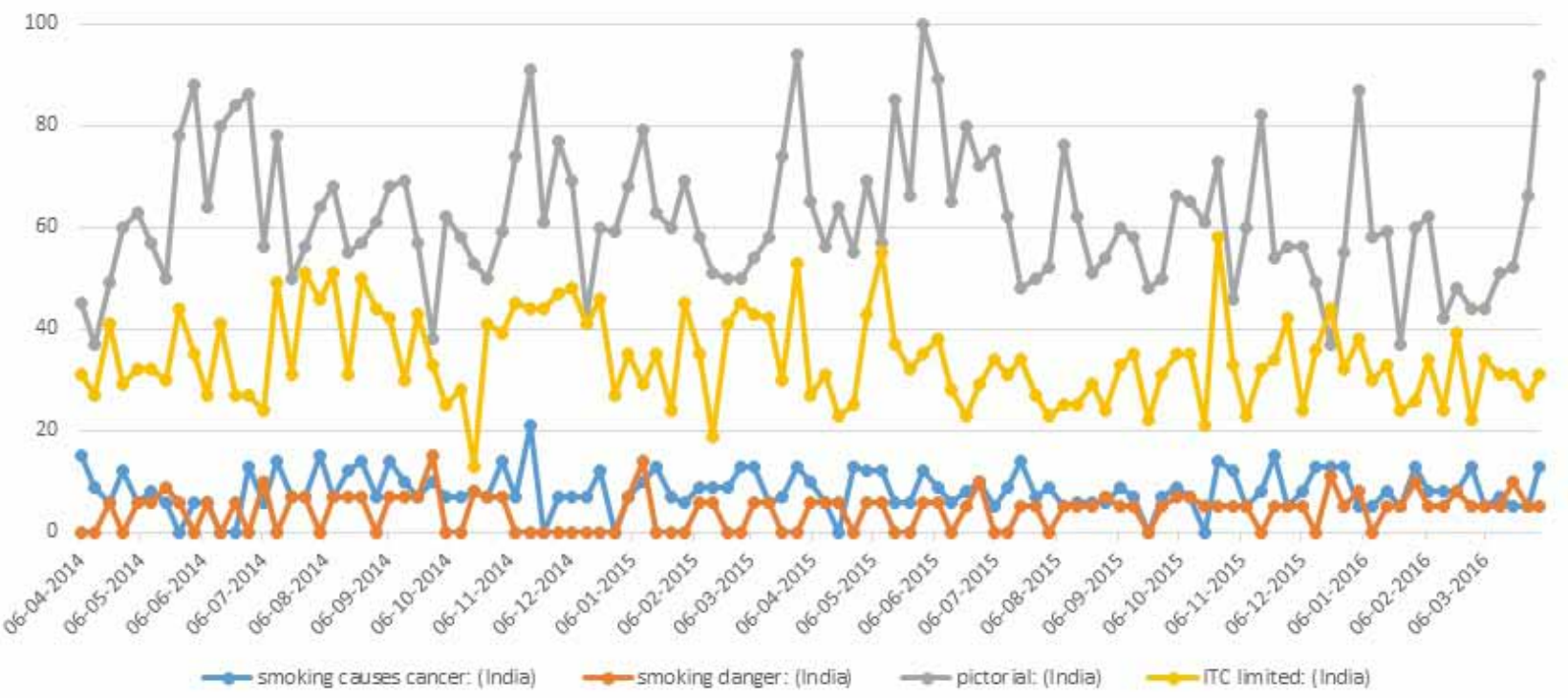

Fig. 1: Pictorial Warnings Timeline and Google keyword searches 
ENDS Ban Timeline and google keyword searches graph

25

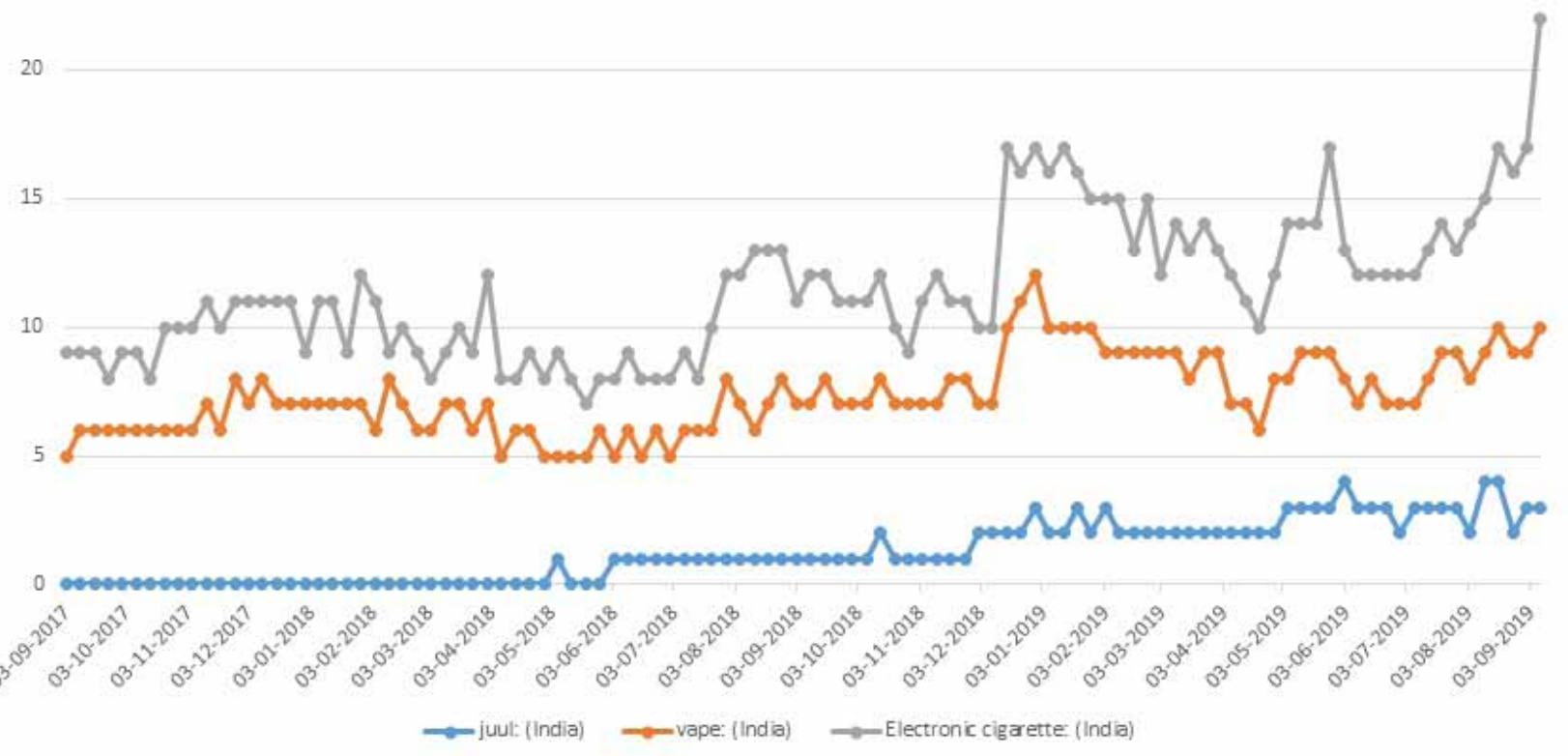

Fig. 2: ENDS Ban Timeline and Google keyword searches

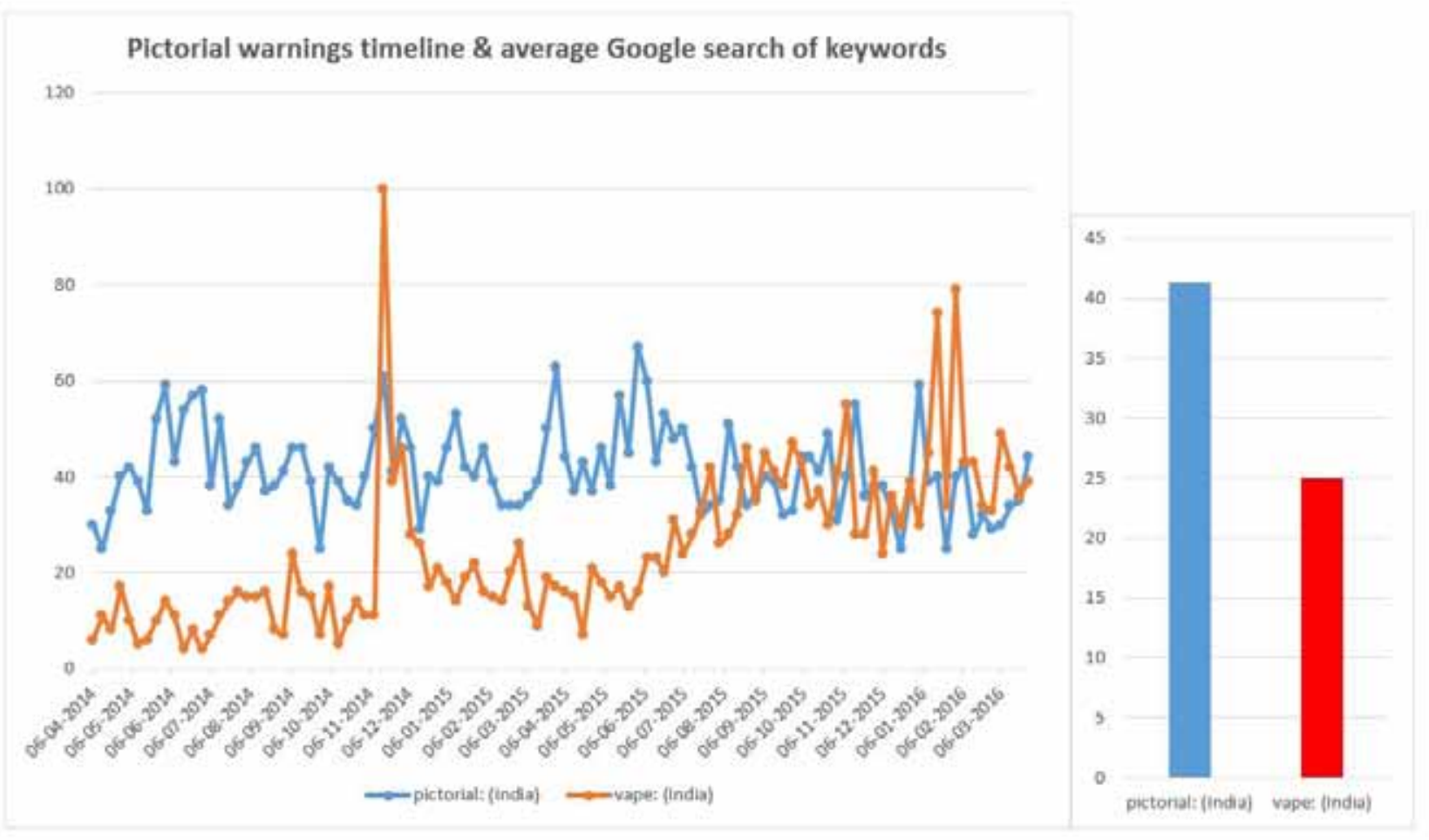

Fig. 3: Pictorial Warnings timeline and average Google search 


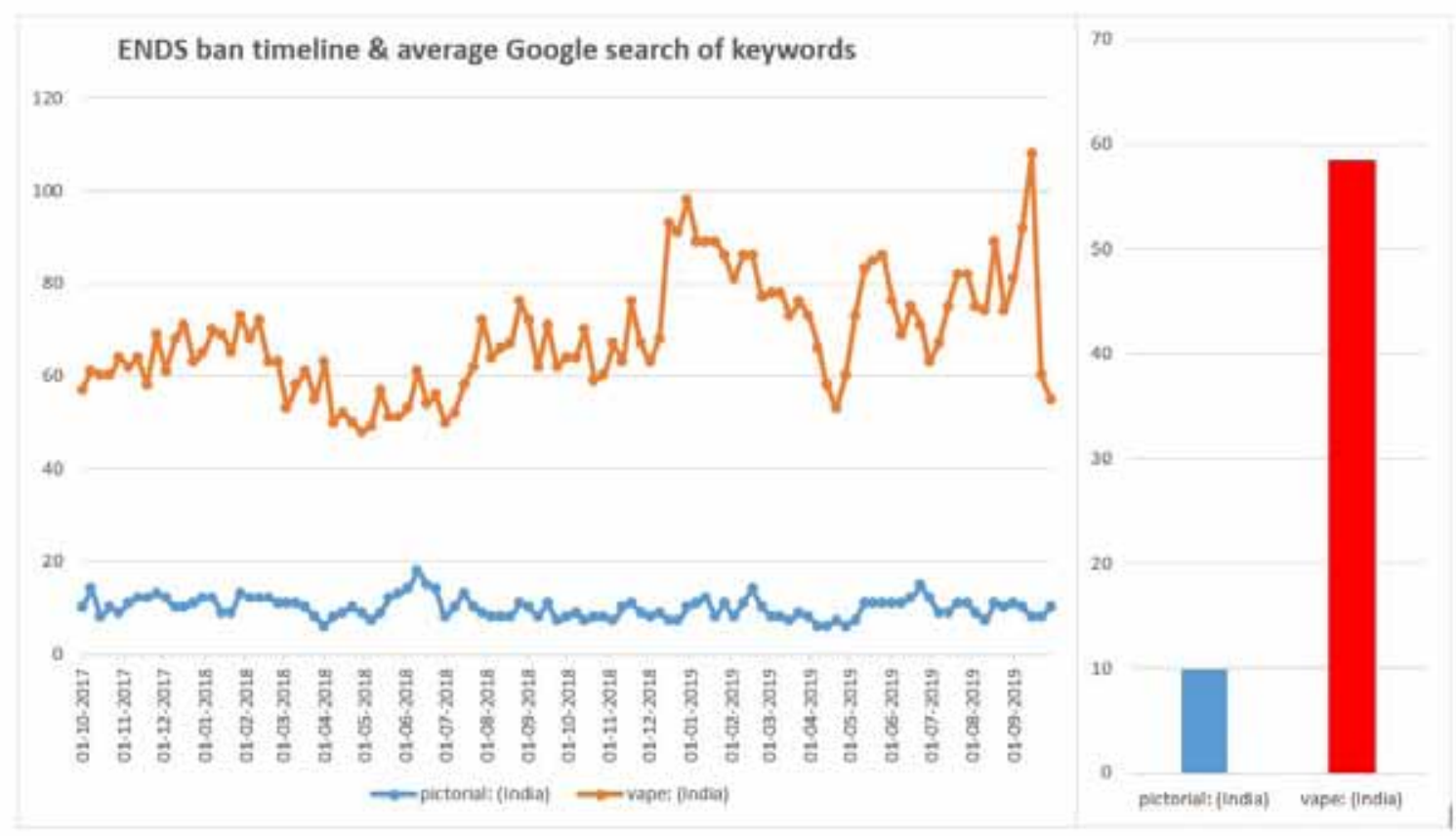

Fig-4: ENDS Ban timeline and average Google search
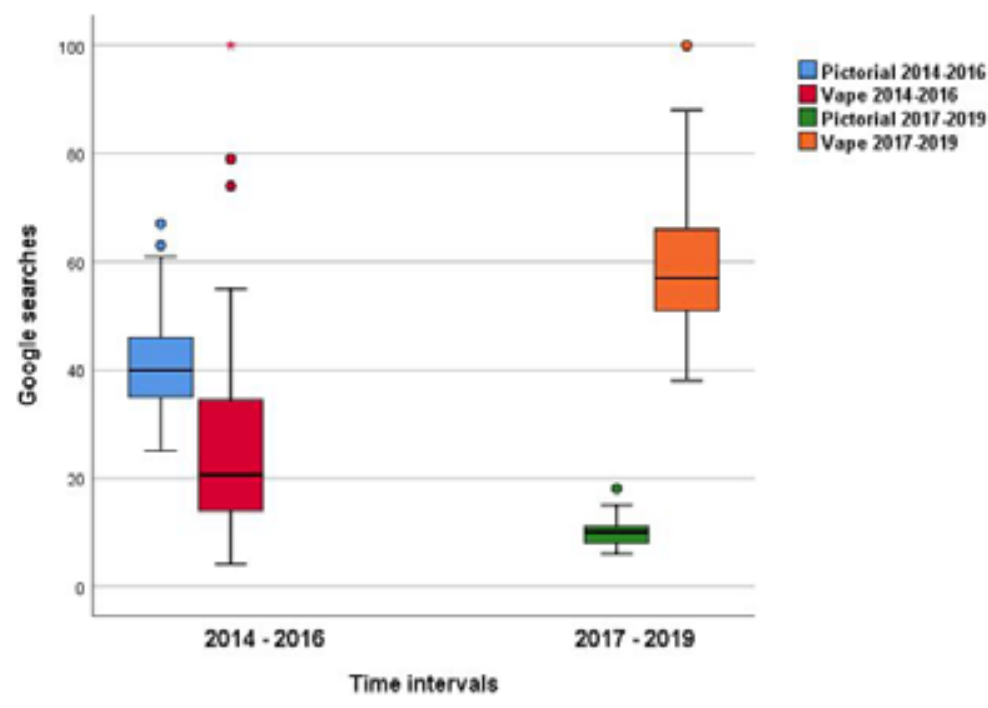

Figure 5 . Volume of difference between the time periods for google search words 'Vape' and 'Pictorial'

\section{Discussion}

Tobacco is a product, if consumed as it is, kills half of its users ${ }^{9}$. As per the World Health Organization, it kills 8 million people every year, globally. Tobaccorelated deaths and disease burden are maximum from the low-and middle-income countries ${ }^{2}$. In India, there are 1.3 million deaths every year due to tobacco use ${ }^{10}$. India has a very effective tobacco control policy which focuses on reduction of prevalence. Large Pictorial
Health Warnings policy is an important deterrent for smoking initiation amongst non-smokers. It also promotes smoking cessation behaviour in the current smokers ${ }^{11}$. Previously, pictorial health warnings in India covered $40 \%$ of the front panel of packets of the tobacco products. Tobacco industry interference was profoundly seen against the implementation of $85 \%$ pictorial health warnings in India due its proven efficacy for tobacco control $^{1}$. Similarly, few years later, there was a perceived threat of logarithmic spread of Electronic cigarettes 
amongst the youth demographic of India. The United States had already seen its growing influence on its future generation with its prevalence being as high as $37.7 \%$ in their high school students ${ }^{12}$. As a result, there were 2,601 lung injuries requiring hospital admission and 59 deaths in the USA ${ }^{13}$. Thus, Electronic Nicotine Delivery Systems (ENDS) ban in India came right on time. India is a developing country and implementation of policies remains a big challenge. Even so, the Government took immediate actions in the direction of banning ENDS, before it could spread its roots in the country. Western world companies had already planned to set up industries in India and were promoting these as less harmful and an alternative to quit smoking ${ }^{14}$. There was no research on the statements made by the ENDS manufacturing industry and the medical fraternity unanimously stood against it in India. In fact, in one of the instances more than 1000 medical doctors wrote to the Prime Minister to ban ENDS immediately as it contained unregulated levels of nicotine with the potential to cause neural damage ${ }^{15,16}$. This paper analysed the resistance faced by the government and other tobacco control stakeholders in enlarging the pictorial health warnings from $40 \%$ to $85 \%$ even after its notification in October 2014. In implementation of $85 \%$ pictorial health warnings, India witnessed a delay of 12 months from the scheduled to actual implementation whereas policy on ENDS ban moved much faster right from advisory by the Ministry to research to Ordinance to passing of Bill in the Parliament of India. This study, therefore, shows in conclusion that there was significant uncertainty about policy implementation of $85 \%$ PW until it was finally implemented on April 1, 2016 whereas in ENDS the Government events were all in favour of the policy. This study also deduces that there was contrasting difference in the fall of events in making of two policies. On the one hand, there were intense false propaganda by tobacco industry which delayed the process the implementation of the Policy A by more than 12 months while on other hand, the government, and many other jurisdictions, civil society, medical fraternity were equipped enough due to earlier hardships faced during policy A implementation leading to expedite release of the White paper against ENDS. Unlike during policy A, anti-tobacco warriors had local study, i.e., the White Paper as an evidence available against $\operatorname{ENDS}^{7}$.

Government does take into account the public opinion, which in turn shapes policies. The Google searches clearly depict the public interest on both the issues in India. Public interest was present for all the keywords representing pictorial health warnings like "smoking causes cancer", "smoking danger", "pictorial”, “TC limited". Similarly,people searched for words related to electronic cigarettes like "Vape", "Juul", "e-cig". As described before, there was a lot of communication from October 2014 to April 2016 till the eventual implementation of enhanced pictorial health warnings. This is truly represented by the google search volumes in those time periods appreciated in the Figure 2. Similarly, there was surge in public interest for policy B events during the month of September (month in which the ordinance was passed). Thus, our results validated our keywords search representing public interest in those periods. We tried to compare the public interest between two policies and found that pictorial was searched more during the policy A time period and Vape was searched more in Policy B time period. However, when the difference of volume of searched keywords was compared, vape representing ENDS was found to be significantly higher. Thus, our google trends analysis suggested that the issue of ENDS was more popular than pictorial health warnings and that the obstacles faced by the Government during the implementation of PWs provided them with much needed insight about the adoption and enforcement of stricter time lines for banning ENDS.

Limitations: Though keywords rightly depicted the peak of the events in our study representing public interest but whether the interest was for or against is unknown. In the PWs policy implementation, there were hearings in the Rajasthan High Court but only those involving the MoHFW announcements are considered.

Novelty of the Study: This is the first study in the literature to sequentially describe detailed pro and antievents which led to the delay of the implementation of pictorial health warnings.

This is also the first study to compare the levels of public interest between two health policies in India.

Implications: Descriptive analysis of events between two policies with differing results would better equip tobacco control organisations for future policy implementation.

Google trends analysis can be a quick, costeffective adjunctive tool to assess the public interest thus redefining expensive traditional method. 


\section{Conclusion}

Intense tobacco control efforts during pictorial health warnings implementation led down a pathway for future policy implementation including ENDS ban. Public interest may also play a pivotal role in hastening policy enactment process as depicted in ENDS ban.

Ethical Clearance: Patients/Subjects were not included in the study.

\section{Source of Funding: Self}

Conflict of Interest: (If any then mention it otherwise write it as nil): Nil

\section{References}

1. Reitsma MB, Fullman N, Ng M, Salama JS, Abajobir A, Abate KH, et al. Smoking prevalence and attributable disease burden in 195 countries and territories, 1990-2015: a systematic analysis from the Global Burden of Disease Study 2015. The Lancet. 2017 May 13;389(10082):1885-906.

2. Organisation mondiale de la santé. WHO report on the global tobacco epidemic, 2017: monitoring tobacco use and prevention policies. 2017.

3. Chopra A, Rao NC, Gupta N, Vashisth S. Communicating tobacco health risks: How effective are the warning labels on tobacco products? Niger Med J J Niger Med Assoc. 2014;55(5):411-6.

4. Balhara YPS, Gupta R. Revised Size of Pictorial Warning on Cigarette Packages-A Step in Right Direction. Nicotine Tob Res. 2015 Nov 1;17(11):1401-2.

5. Purcell K, Rainie L, Brenner J. Search engine use 2012.

6. Nuti SV, Wayda B, Ranasinghe I, Wang S, Dreyer RP, Chen SI, et al. The Use of Google Trends in Health Care Research: A Systematic Review. Voracek M, editor. PLoS ONE. 2014 Oct 22;9(10):e109583.

7. Chakma JK, Dhaliwal RS, Mehrotra R. White Paper on Electronic Nicotine Delivery System. Indian J Med Res. 2019 May;149(5):574-83.
Medico-legal Update, April-June 2021, Vol. 21, No. 2

217

8. Rao US V, Arakeri G, Ravishankar S, Kar A, Thakur S, Li RJ, Dhananjay KV, Surya T, Chaturvedi P, Gomez RS, Brennan PA. The E-cigarette ban in India-A step in the right direction?. Journal of Oral Pathology \& Medicine. 2020.

9. Kumar A, Puranik MP. Pictorial health warnings on tobacco packs-a knowledge, attitude and practice survey among Indian engineering students. Int $\mathbf{J}$ Health Sci. 2017;1.

10. FAQs: National Health Mission [Internet]. [cited 2020 Jun 7]. Available from: https://nhm.gov.in/ index 1.php?lang=1 \& level=3 \& sublinkid=1122 \& lid $=640$

11. Ratih SP, Susanna D. Perceived effectiveness of pictorial health warnings on changes in smoking behaviour in Asia: a literature review. BMC Public Health. 2018 Oct 11;18(1):1165.

12. Health $\mathrm{CO}$ on $\mathrm{S}$ and. Smoking and Tobacco Use; Data and Statistics; Surveys; National Youth Tobacco Survey (NYTS) [Internet]. Smoking and Tobacco Use. 2019 [cited 2020 Jun 7]. Available from: http://www.cdc.gov/tobacco/data_statistics/ surveys/nyts/

13. Health $\mathrm{CO}$ on $\mathrm{S}$ and. Smoking and Tobacco Use; Electronic Cigarettes [Internet]. Centers for Disease Control and Prevention. 2020 [cited 2020 Jun 7]. Available from: https://www.cdc.gov/ tobacco/basic_information/e-cigarettes/severelung-disease.html

14. Medicine TLR. Smoking cessation efforts should target LMICs. Lancet Respir Med. 2019 Sep 1;7(9):721.

15. Over 1,000 doctors across India write to PM Modi to continue ban on e-cigarettes | India News, The Indian Express [Internet]. [cited 2020 Jun 5]. Available from: https://indianexpress.com/article/ india/over-1000-doctors-across-india-write-to-pmmodi-to-continue-ban-on-e-cigarettes-5642820/

16. Goriounova NA, Mansvelder HD. Short-and longterm consequences of nicotine exposure during adolescence for prefrontal cortex neuronal network function. Cold Spring Harbor perspectives in medicine. 2012 Dec 1;2(12):a012120. 